\title{
Catalytic Properties of Hierarchical Mesoporous Zeolites Templated with a Mixture of Small Organic Ammonium Salts and Mesoscale Cationic Polymers**
}

Feng-Shou Xiao ${ }^{1, *}$, Lifeng Wang ${ }^{1}$, Chengyang Yin ${ }^{1}$, Kaifeng Lin ${ }^{1}$, Yan Di ${ }^{1}$, Jixue Li ${ }^{1}$, Ruren $\mathrm{Xu}{ }^{1}$, Dang Sheng Su ${ }^{2}$, Robert Schlögl ${ }^{2}$, Toshiyuki Yokoi ${ }^{3}$, and Takashi Tatsumi ${ }^{3}$

${ }^{1}$ State Key Laboratory of Inorganic Synthesis and Preparative Chemistry, College of Chemistry, Jilin University, Changchun 130012 (P.R. China)

${ }^{2}$ Abteilung für Anorganische Chemie, Fritz-Haber-Institut der Max-Planck-Gesellschaft, Faradayweg 4-6, 14195 Berlin (Germany)

${ }^{3}$ Chemical Resources Laboratory, Tokyo Institute of Technology, 4259 Nagatsuta-cho, Midori-ku, Yokohama 226-8503 (Japan)

* corresponding author. Fax: (+86) 431-516-8624, E-mail: fsxiao@mail.jlu.edu.cn

** This work was supported by the National Natural Science Foundation of China (20573044, 20373018, 20233030), the State Basic Research Project of China (2004CB217804 and 2003CB615802), and the Ministry of Education, China. We thank Prof. D. Z. Jiang and Prof. S. J. Ma for helpful discussions.

Keywords: amines, heterogeneous catalysis, polymers, template synthesis, zeolites

Crystals of zeolites with intricate micropores have been widely used in industry as heterogeneous catalysts, in particular as solid acid catalysts in the fields of oil refining and petrochemistry. However, relatively small individual micropores in zeolites such as Beta, ZSM-5, and Y strongly influence mass transport to and from the active sites located within them, severely limiting the performance of industrial catalysts.[1,2] To overcome this problem, various strategies have been successfully pursued, such as the synthesis of nanosized zeolites,[3] ultralarge-pore zeolites and zeolite analogues (VPI-5,[4] JDF-20,[5] UTD-1,[6, 7] CIT-5,[8] SSZ-53,[9] ECR-34,[10] UCSB,[11] ITQ-21,[12] IM-12,[13] and SU-M,[14, 15] among others), and ordered mesoporous materials (e.g. MCM-41,[17] SBA-15,[18] and FSM-16,[19]). However, the use of these materials is rather limited owing to the difficult separation of nanosized zeolite crystals from the reaction mixture,[3] the complexity of the templates used for the synthesis of ultralarge-pore zeolites,[6-9] and the relatively low thermal and hydrothermal stability of ordered mesoporous materials.[17-28] More recently, mesoporous zeolites from nanosized carbon templates have also been successfully synthesized,[29-32] but their industrial applications are still limited by the complexity of the synthetic procedure involved and the hydrophobicity of the carbon templates.

Herein, we demonstrate a facile, controllable, and universal route for the synthesis of hierarchical mesoporous zeolites templated from a mixture of small organic ammonium salts and mesoscale cationic polymers. The route involves a one-step hydrothermal synthesis, and the templated mixture is homogeneously dispersed in the synthetic gel. Importantly, these novel zeolites exhibit excellent catalytic properties compared with conventional zeolites. This work may give an entry to the synthesis of hierarchical mesoporous zeolites that reveal fast mass transport, with potential application in industrial catalysis.

Beta zeolite is generally synthesized from a small organic template of tetraethylammonium hydroxide (TEAOH). In the present strategy, hierarchical mesoporous Beta zeolite (Beta-H) was crystallized in the presence of TEAOH and a mesoscale cationic polymer, polydiallyldimethylammonium chloride (PDADMAC). For comparison, conventional Beta zeolite was prepared in the absence of cationic polymer by a similar procedure.

The X-ray diffraction (XRD) pattern of calcined Beta-H (Figure 1a) shows well-resolved peaks in the $4-40^{\circ}$ range, characteristic for the Beta zeolite structure.[33] Interestingly, $\mathrm{N}_{2}$ 
adsorption/desoption isotherms of calcined Beta-H exhibit a step at a relative pressure, $\mathrm{P} / \mathrm{P}_{0}$, of 0.8-0.95, as a result of the presence of mesostructures (Figure 1b). Correspondingly, the poresize distribution for calcined Beta-H shows mesopores at 5-40 nm (Figure 1b, inset). These results indicate that the Beta-H sample contains mesostructures, which may be of importance for mass transport.[1, 2]

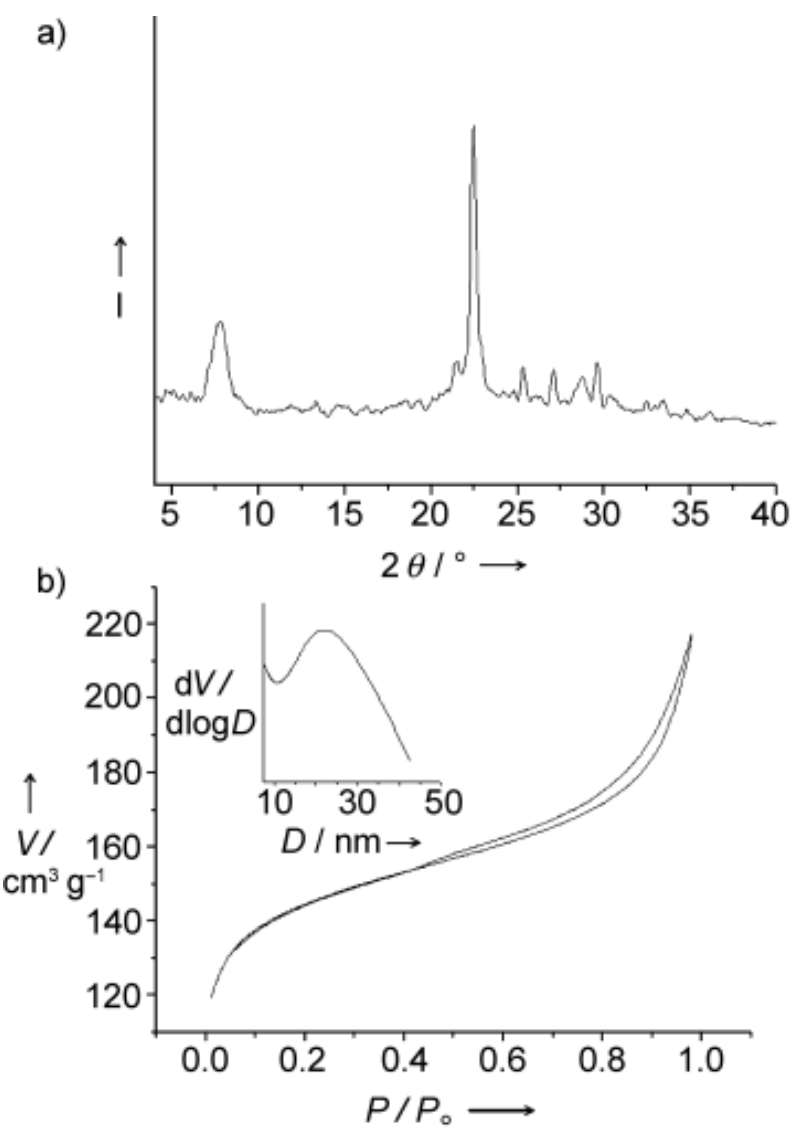

Figure 1. Analyses of the sample of calcined Beta-H: a) XRD pattern; b) $\mathrm{N}_{2}$ adsorption/desorption isotherms and pore-size distribution curve (inset).

Low-magnification scanning electron microscopy (SEM) images of the calcined sample of Beta$\mathrm{H}$ (see Figure 2a and Supporting Information) reveal the presence of almost uniformly sized particles (size about $600 \mathrm{~nm}$ ) with similar morphology. Furthermore, SEM images under high magnification (see Figure $2 \mathrm{~b}$ and Supporting Information) clearly show hierarchical mesoporosity in the range of 5-40 nm. Partial connections between these hierarchical pores were observed that could be beneficial for the mass transfer of reactants and products in catalysis. For comparison, the SEM image of the sample of Beta zeolite reveals uniform particles of $300 \mathrm{~nm}$ in size (see Supporting Information), about half the size of the particles in Beta-H.

The transmission electron microscopy (TEM) image of the calcined sample of Beta-H (Figure 2 c) also shows uniformly sized particles, confirming the pure phase of the sample. TEM images under high magnification (see Figure $2 \mathrm{~d}$ and Supporting Information) show both hierarchical mesopores (5-20 nm) and ordered micropores in the sample of Beta-H. Note that the micropores with a size of around $0.8 \mathrm{~nm}$, which are related to typical pores of Beta zeolite crystals, are ordered.[34] Hierarchical mesopores are partially continuous and open at the external surface of the sample, and crystal walls are partially connected to each other. Relative to conventional ordered mesoporous materials, the pore size of the mesopores in the Beta-H sample is relatively wide, which confirms hierarchical mesoporosity and is again of importance for mass transport.[1, 2] 


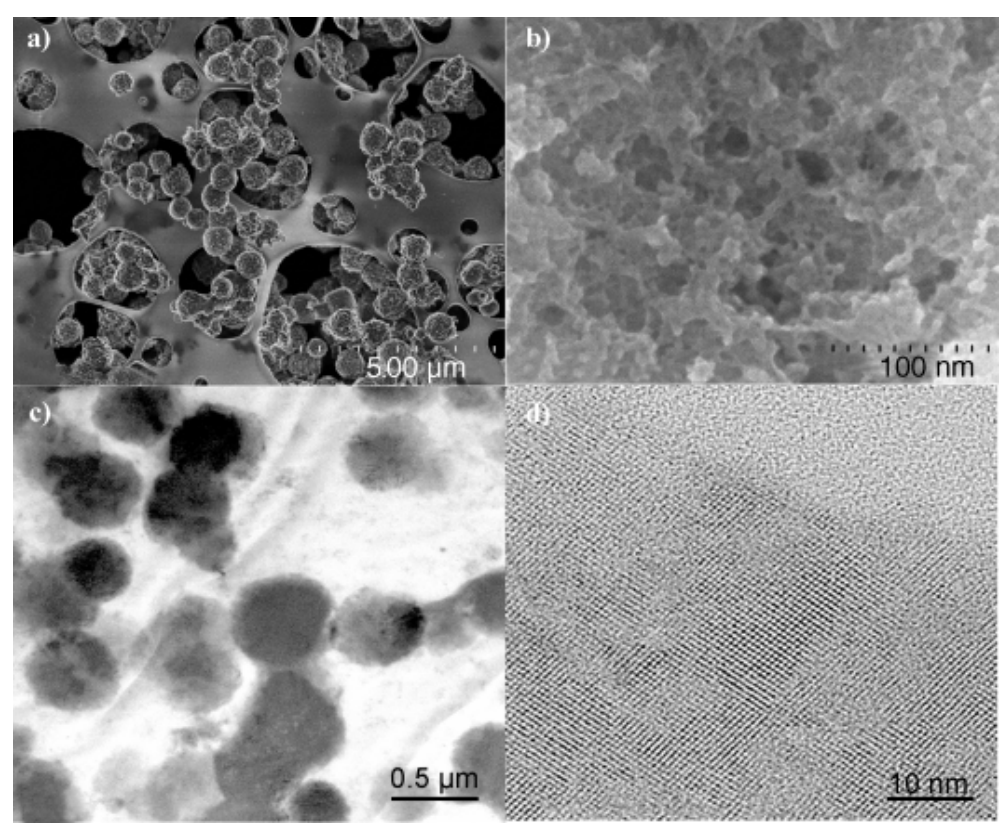

Figure 2. Electron microscopy images of calcined Beta-H: a, b) SEM images at low and high magnification, respectively (the separation between each marker represents $5 \mu \mathrm{m}$ and $100 \mathrm{~nm}$, respectively); c, d) TEM images at low and high magnification, respectively.

Thermogravimetric analysis (TGA) of the sample of Beta- $\mathrm{H}$ shows a weight loss of $32.9 \%$ owing to the removal of the organic templates, TEAOH and the cationic polymer (see Supporting Information). In contrast, the sample of conventional Beta zeolite exhibits a total weight loss of $22.2 \%$. The larger weight loss in Beta- $\mathrm{H}$ is assigned reasonably to the removal of the cationic polymer in the sample, and the results also suggest that Beta-H reveals a larger pore volume and more-complex porosity. The alkylation of benzene with propan-2-ol over various Beta zeolites was investigated as a model catalytic reaction. Figure 3 shows the dependence of the catalytic activity and selectivity on the reaction time in the alkylation reaction. Surprisingly, the Beta-H sample shows a high activity and selectivity as a catalyst, as well as a long catalyst life relative to the sample of conventional Beta zeolite. The similarities of Beta- $\mathrm{H}$ to conventional Beta zeolite in terms of $\mathrm{Si} / \mathrm{Al}$ ratios, aluminum distribution, and acidic strength, as well as the larger particle size of Beta-H than that of Beta zeolite indicate that the higher catalytic activity of Beta- $\mathrm{H}$ in the model alkylation reaction relates to the mesoporosity in the Beta-H sample. These results also show that the presence of hierarchical mesopores in the sample of Beta- $\mathrm{H}$ is important for the mass transport of the reactants and products in the alkylation of benzene with propan-2-ol.

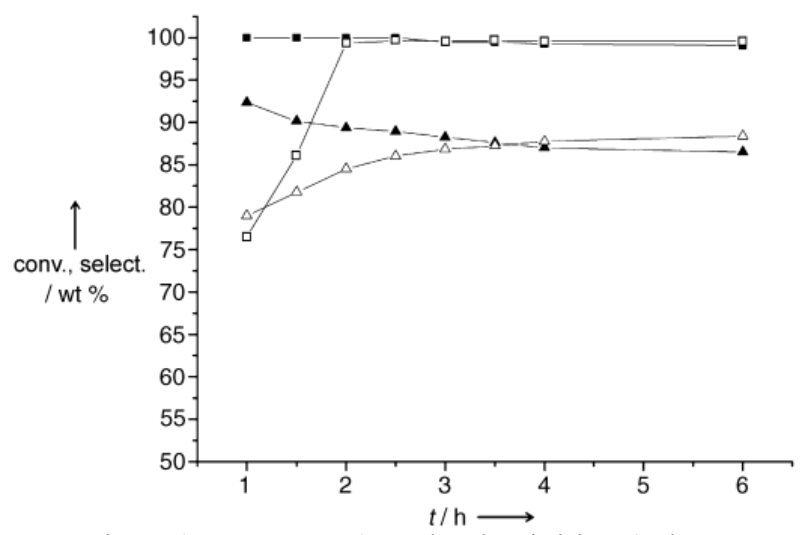

Figure 3. Catalytic conversions (conv. [wt\%]) and selectivities (select. [wt \%]) in the alkylation of benzene with propan-2-ol with various zeolites samples as a function of reaction time (reaction temperature: $200 \mathrm{C}$; 4:1 benzene/ propan-2-ol; reaction pressure: 2.0 MP, weight hourly spare velocity (WHSV): $10 \mathrm{~h}^{-1}$ ). Conversion on Beta-H (घ); selectivity on Beta-H $(\square)$; conversion on Beta zeolite $(\boldsymbol{\Delta})$; selectivity on Beta zeolite $(\Delta)$. 
The presence of hierarchical mesoporosity in the Beta-H sample is attributed to the use of the molecular and aggregated cationic polymer PDADMAC. The molecular weight of the cationic polymer lies in the range $1 \times 10^{5}-1 \times 10^{6}$, and its size is estimated at $5-40 \mathrm{~nm}$, which is in good agreement with the dimensions of the mesopores obtained from high-resolution (HR)TEM studies (Figure $2 \mathrm{~d}$ ). The cationic polymers could effectively interact with negatively charged inorganic silica species in alkaline media, resulting in the hierarchical mesoporosity. The addition of a greater amount of cationic polymer in the synthetic gel yields Beta zeolite with larger mesoporosity, indicating the controllable mesoporosity of the zeolite sample.

The synthesis of hierarchical mesoporous zeolites is not limited to the Beta variety, which was obtained through use of TEAOH with PDADMAC, but other mixtures of organic amine salts and cationic polymer templates may be used if they effectively interact with inorganic species in alkaline media under conditions to crystallize the zeolites. This method opens the door for the hierarchical mesoporous zeolites, such as ZSM-5, Y, TS-1, and so on. For example, hierarchical mesoporous ZSM-5zeolite (ZSM-5-H) was obtained using a mixture of tetrapropylamine hydroxide and dimethyldiallyl ammonium chloride acrylamide copolymer (10 $\mathrm{wt} \%)$, and its hierarchical mesoporosity was characterized by XRD, $\mathrm{N}_{2}$ adsorption/desorption isotherms, SEM, and HRTEM techniques (see Supporting Information). Particularly, use of the hierarchical mesoporous sample ZSM-5-H in the catalytic cracking of 1,3,5-triisopropylbenzene showed that it is much more active a catalyst than conventional ZSM-5under the same reaction conditions (see Supporting Information).

\section{Experimental Section}

In a typical synthesis of hierarchical mesoporous Beta zeolite (Beta- $\mathrm{H}), \mathrm{NaOH}(0.16 \mathrm{~g})$ and $\mathrm{NaAlO}_{2}(0.30 \mathrm{~g})$ were mixed with tetraethylammonium hydroxide (TEAOH; $25-35 \mathrm{~mL}, 20-25 \mathrm{wt}$ $\%$ ), and fumed silica $\left(\mathrm{SiO}_{2}, 4.8 \mathrm{~g}\right)$ was then added. After stirring the mixture for $1 \mathrm{~h}$ at room temperature, cationic polymer polydiallyldimethylammonium chloride (PDADMAC; 0.4-4.0 g, $40 \mathrm{wt} \%$ ) was added. After stirring for 10-24 h at room temperature, the mixture was transferred into an autoclave at $140^{\circ} \mathrm{C}$ for $120-240 \mathrm{~h}$ for further crystallization. The product was collected by filtration, dried in air, and calcined at $550^{\circ} \mathrm{C}$ for $5 \mathrm{~h}$ to remove the template. For comparison, conventional Beta zeolite was synthesized by the same procedure except for the absence of cationic polymer.

In a typical synthesis of hierarchical mesoporous ZSM-5zeolite (ZSM-5-H), $\mathrm{NaAlO}_{2}(0.08 \mathrm{~g})$, tetrapropylammonium hydroxide (TPAOH; 4-12 mL, 20-25wt \%), and tetraethyl orthosilicate

(TEOS; $7.0 \mathrm{~mL}$ ) were mixed with $\mathrm{H}_{2} \mathrm{O}(20.0 \mathrm{~mL})$ under stirring and aged at $100^{\circ} \mathrm{C}$ for $1.5-3 \mathrm{~h}$. Then, cationic polymer dimethyldiallyl ammonium chloride acrylamide copolymer (PDD-AM; 0.5-8.0 g, $10 \mathrm{wt} \%$ ) was added to the reaction mixture. After stirring for 12-48 $\mathrm{h}$ at room temperature, the mixture was transferred into an autoclave at $180^{\circ} \mathrm{C}$ for $120-240 \mathrm{~h}$ for further crystallization. The product was collected by filtration, dried in air, and calcined at $550^{\circ} \mathrm{C}$ for $5 \mathrm{~h}$ to remove the template. For comparison, standard ZSM-5zeolite was synthesized under the same conditions except for the absence of cationic polymer. Furthermore, larger crystals of ZSM5zeolite (ZSM-5-F) were synthesized by a similar procedure with the addition of $\mathrm{NH}_{4} \mathrm{~F}(1.2 \mathrm{~g})$ and in the absence of cationic polymer.

XRD patterns were obtained with a Siemens D5005 diffractometer using $\mathrm{Cu}_{\mathrm{K} \alpha}$ radiation. Nitrogen adsorption and desorption isotherms at $77 \mathrm{~K}$ were measured using a Micromeritics ASAP 2010M system. The samples were degassed for $10 \mathrm{~h}$ at $300^{\circ} \mathrm{C}$ before the measurements. SEM experiments were performed on Hitachi S- 5200 and Hitachi S-4000 electron microscopes. TEM experiments were performed on a Philips CM $200 \mathrm{LaB}_{6}$ operating at $200 \mathrm{kVand}$ a JEM3010 electron microscope (JEOL, Japan) with an acceleration voltage of $300 \mathrm{kV}$. Differential thermal analysis and TGA studies were performed with Perkin-Elmer TGA7 and DTA-1700 apparatus, respectively. [27] Al MAS NMR measurements were performed on a Varian Infinity plus 400 spectrometer. Ratios of $\mathrm{Si} / \mathrm{Al}$ in the samples were determined by the results of inductively coupled plasma analysis (ICP, Perkin-Elmer 3300DV) and chemical analysis. 
Temperatureprogrammed desorption of ammonia (NH3-TPD) curves were obtained in the range $120-600^{\circ} \mathrm{C}$, where the temperature was increased at a rate of $15^{\circ} \mathrm{Cmin}^{-1}$.

\section{References}

[1] M. E. Davis, Nature 2002, 417, 813 - 821.

[2] M. Hartmann, Angew. Chem. 2004, 116, 6004 - 6006; Angew. Chem. Int. Ed. 2004, 43, 5880 - 5882.

[3] B. J. Schoeman, J. Sterte, J. E. Otterstedt, Zeolites 1994, 14, 110 - 116.

[4] M. E. Davis, C. Saldarriaga, C. Montes, C. Garces, C. Crowder, Nature 1988, 331, $698-699$.

[5] Q. Huo, R. Xu, S. Li, Z. Ma, J. M. Thomas, R. Jones, A. Chippindale, J. Chem. Soc. Chem. Commun. $1992,875-876$.

[6] C. C. Freyhardt, M. R. Tsapatsis, F. Lobo, K. J. Balkus, M. E. Davis, Nature 1996, 381, 295- 298.

[7] a) T. Wessels, C. Baerlocher, L. B. McCusker, Science 1999, 284, 477 - 479; b) T. Wessels, C.

Baerlocher, L. B. McCusker, E. J. Creyghton, J. Am. Chem. Soc. 1999, 121, $6242-6247$.

[8] P. Wagner, M. Yoshikawa, T. Katsuyuki, M. E. Davis, M. Lovallo, M. Taspatsis, Chem. Commun. $1997,2179-2180$.

[9] A. Burton, S. Elomari, C.-Y. Chen, R. C. Medrud, I. Y. Chan, L. M. Bull, C. Kibby, T. V. Harris, S. I. Zones, E. S. Vittoratos, Chem. Eur. J. 2003, 9, $5737-5748$.

[10] K. G. Strohmaier, D.W. Vaughan, J. Am. Chem. Soc. 2003, 125, 16035- 16039.

[11] X. Bu, P. Feng, G. D. Stucky, Science 1997, 278, 2080 - 2085.

[12] A. Corma, M. Diaz-Cabanas, J. Martinez-Triguero, F. Rey, J. Rius, Nature 2002, 418, 514 - 517.

[13] J.-L. Paillaud, B. Harbuzaru, J. Patarin, N. Bats, Science 2004, 304, 990 - 992.

[14] X. Zou, T. Conradsson, M. Klingstedt, M. S. Dadachov, M. OKKeeffe, Nature 2005, 437, 716 - 719.

[15] H. Gies, Nature 2005, 437, $633-633$.

[16] J. Zhu, X. Bu, P. Feng, G. D. Stucky, J. Am. Chem. Soc. 2000, 122, 11563 - 11564.

[17] C. T. Kresge, M. E. Leonowicz, W. J. Roth, J. C. Vartuli, J. S. Beck, Nature 1991, 352, 710 - 712.

[18] D. Zhao, J. Feng, Q. Huo, N. Melosh, G. H. Fredrickson, B. F. Chmelka, G. D. Stucky, Science, $1998,279,548-552$.

[19] S. Inagaki, Y. Fukushima, K. Kuroda, J. Chem. Soc. Chem. Commun. 1993, $680-682$.

[20] A. Corma, Chem. Rev. 1997, 97, 2373 - 2420.

[21] K. Landskron, G. A. Ozin, Science 2004, 306, 1529 - 1532.

[22] S. A. Johnson, P. J. Ollivier, T. E. Mallouk, Science 1999, 283, 963 - 965.

[23] a) Y. Liu,W. Zhang, T. J. Pinnavaia, J. Am. Chem. Soc. 2000, 122, 8791 - 8792; b) Y. Liu, W. Zhang, T. J. Pinnavaia, Angew. Chem. 2001, 113, 1295- 1298; Angew. Chem. Int. Ed. 2001, 40, $1255-1258$.

[24] a) Z. Zhang, Y. Han, L. Zhu, R.Wang, Y. Yu, S. Qiu, D. Zhao, F.- S. Xiao, Angew. Chem. 2001, 113, 1298 - 1302; Angew. Chem. Int. Ed. 2001, 40, 1258 - 1262; b) F.-S. Xiao, Y. Han, X.-J. Meng, Y. Yu, M. Yang, S. Wu, J. Am. Chem. Soc. 2002, 124, $888-889$.

[25] H. Gies, S. Grabowski, W. Grunert, Stud. Surf. Sci. Catal. 2004, 154, 2869 - 2875.

[26] a) D. T. On, S. Kaliaguine, Angew. Chem. 2001, 113, 3348 - 3351; Angew. Chem. Int. Ed. 2001, 40, 3248 - 3251; b) D. T. On, S. Kaliaguine, J. Am. Chem. Soc. 2003, 125, $618-619$.

[27] a) C. E. A. Kirschhock, S. P. B. Kremer, J. Vermant, G. Van Tendeloo, P. A. Jacobs, J. A. Martens, Chem. Eur. J. 2005, 11, 4306 - 4313; b) S. P. B. Kremer, C. E. A. Kirschhock, A. Aerts, K. Villani, J. A. Martens, O. I. Lebedev, G. Van Tendeloo, Adv. Mater. 2003, 15, 1705- 1707.

[28] F. SchLth, Angew. Chem. 2003, 115, 3730 - 3750; Angew. Chem. Int. Ed. 2003, 42, $3604-3622$.

[29] C. J. H. Jacobsen, C. Madsen, J. Houzvicka, I. Schmidt, A. Carlsson, J. Am. Chem. Soc. 2000, 122, $7116-7117$.

[30] Y. Tao, H. Kanoh, K. Kaneko, J. Am. Chem. Soc. 2003, 125, $6044-6045$.

[31] Z. Yang, Y. Xia, R. Mokaya, Adv. Mater. 2004, 16, 727 - 732.

[32] W.-C. Li, A.-H. Lu, R. Palkovits, W. Schmidt, B. Spliethoff, F. SchLth, J. Am. Chem. Soc. 2005, $127,12595-12600$.

[33] M. M. J. Treacy, J. B. Higgins, Collection of Simulated XRD Powder Patterns for Zeolites, 4th ed., Elsevier, Amsterdam, 2001.

[34] M. K. Rubin, European Patent 0159846, 1985.

Supporting information for this article is available on the WWW under http://www.angewandte.org or from the author 